\title{
Correction to: The Future of Europe
}

\author{
Michael Kaeding, Johannes Pollak, and Paul Schmidt
}

\section{Correction to:}

M. Kaeding et al. (eds.), The Future of Europe

https://doi.org/10.1007/978-3-319-93046-6

The original version of this book was inadvertently published without the following disclaimer:

The European Commission support for the production of this publication does not constitute an endorsement of the contents which reflects the views only of the authors, and the Commission cannot be held responsible for any use which may be made of the information contained therein.

The disclaimer has now been added to the copyright page of the book.

The updated online version of the book can be found at https://doi.org/10.1007/978-3-319-93046-6

(C) The Author(s) 2019 